\title{
Depot testosterone in boys with anorchia or gonadotrophin deficiency: effect on growth rate and adult height
}

\author{
B Moorthy, Maria Papadopolou, D G Shaw, D B Grant
}

\begin{abstract}
Eleven teenage boys with bilateral anorchia and 12 with gonadotrophin deficiency were treated by injections of testosterone ester (enanthate) at an initial dose of $100 \mathrm{mg}$ every six to eight weeks, rising to $250 \mathrm{mg}$ every four weeks after three to four years. In the anorchic boys average adult height was $177.1 \mathrm{~cm}$, compared with a mean mid-parental height of $174.4 \mathrm{~cm}$, and mean predicted adult heights of $177.0 \mathrm{~cm}$ (Tanner-Whitehouse method) and $178.0 \mathrm{~cm}$ (Bayley-Pinneau method). In the patients with gonadotrophin deficiency, mean adult height was $176.9 \mathrm{~cm}$, compared with a mean mid-parental height of $176.1 \mathrm{~cm}$, and mean predicted adults heights of $174.0 \mathrm{~cm}$ (Tanner-Whitehouse method) and $177.3 \mathrm{~cm}$ (Bayley-Pinneau method). We conclude that this testosterone regimen allows achievement of full growth potential in such patients.
\end{abstract}

During the last 20 years treatment with depot testosterone by intramuscular injection has become well established in the management of boys with different disorders of puberty. Initially introduced for the management of anorchia, ${ }^{12}$ testosterone has been widely used in the management of constitutional delay of puberty, ${ }^{3-5}$ and gonadotrophin deficiency either as an isolated defect or as part of a wider range of anterior pituitary failure. ${ }^{256}$ Though early reports suggested that testosterone treatment might be associated with some reduction in adult height because of rapid advancement in bone age, ${ }^{7}$ it is now believed that treatment with low doses of testosterone has no ill effect on ultimate height. Most of the studies supporting this view, however, have been in patients receiving relatively short term courses of testosterone.

The present retrospective study on the effects of testosterone on boys with anorchia or gonadotrophin deficiency was carried out to confirm that the testosterone regimen that had been used had no significant ill effects on adult height. The study also provided an opportunity to compare two different methods of assessing bone age and predicting adult height.

Hospital for

Sick Children,

Great Ormond Street,

London WCIN 3JH

B Moorthy

Maria Papadopolou

D G Shaw

D B Grant

Correspondence to:

Dr Grant.

Accepted 17 August 1990

\section{Patients and methods} PATIENTS

The case notes and radiographs of the hands of 11 boys with anorchia (but otherwise normal genitalia), and 12 with gonadotrophin deficiency, 10 of whom also had hyposmia (Kallman's syndrome), were reviewed. They had all received long term treatment with depot testos- aterone by injection to achieve full masculinistion. Parental heights were known in all the cases.

Surgical exploration had been carried out in 10 of those with anorchia, and the absence of testicular tissue in the remaining case was confirmed by the lack of response to three daily injections of human gonadotrophic hormone (1000 IU). In all these cases basal testosterone concentration was below $1.5 \mathrm{nmol} / 1$ before treatment; concentrations of follicle stimulating hormone and luteinising hormone were above 30 $\mathrm{IU} / 1$ and above $10 \mathrm{IU} / 1$, respectively.

Six of the patients with gonadotrophin deficiency had had orchidopexies for bilateral cryptorchidism. In all these patients basal concentrations of luteinising hormone and follicle stimulating hormone were below $2.6 \mathrm{IU} / 1$, and that of testosterone was less than $1.2 \mathrm{nmol} / \mathrm{l}$ before treatment.

After an initial period of observation, depot testosterone (testosterone enanthate) was started at a mean age of 13.2 years (range 11.0 16.0 ) in the boys with anorchia and $15 \cdot 1$ years (range 12.0-19.7) in those with gonadotrophin deficiency. The difference in the age at start of treatment was the result of later referral of some of the patients with gonadotrophin deficiency, some of whom had previously been thought to have constitutional delay of puberty. Adult heights were obtained for all the patients either from the casenotes (less than $1 \mathrm{~cm}$ growth in six months) or by recalling the patient for measurement. Details of the mean ages and heights at the start of treatment and when growth was complete in the two groups of patients are summarised in table 1 .

Treatment was usually started with an initial dose of $100 \mathrm{mg}$ testosterone enanthate every six to eight weeks; after one to two years the dose

Table 1 Mean (range) height and weight before treatment and age at start of treatment, in 11 boys with anorchia and 12 with gonadotrophin deficiency, together with mean height, weight, and age when last measured

\begin{tabular}{lcc}
\hline & $\begin{array}{l}\text { Boys with anorchia } \\
(n=11)\end{array}$ & $\begin{array}{l}\text { Boys with } \\
\text { gonadotrophin } \\
\text { deficiency } \\
(n=12)\end{array}$ \\
\hline $\begin{array}{c}\text { Age at start of } \\
\text { treatment (years) }\end{array}$ & $13 \cdot 2(11 \cdot 0-16 \cdot 0)$ & $15 \cdot 1(12 \cdot 0-19 \cdot 7)$ \\
$\begin{array}{c}\text { Height at start of } \\
\text { treatment (cm) }\end{array}$ & $152 \cdot 7(131 \cdot 9-169 \cdot 4)$ & $157 \cdot 6(144 \cdot 2-169 \cdot 5)$ \\
$\begin{array}{c}\text { Weight at start of } \\
\text { treatment (kg) }\end{array}$ & $42 \cdot 6(24 \cdot 6-58 \cdot 5)$ & $51 \cdot 2(38 \cdot 5-64 \cdot 4)$ \\
$\begin{array}{c}\text { Age when last } \\
\text { measured (years) }\end{array}$ & $20.4(16 \cdot 2-26 \cdot 7)$ & $21 \cdot 4(17 \cdot 9-29 \cdot 7)$ \\
$\begin{array}{c}\text { Height when last } \\
\text { measured (cm) } \\
\text { Weight when last } \\
\text { measured (kg) }\end{array}$ & $177 \cdot 0(167 \cdot 2-188 \cdot 6)$ & $177 \cdot 8(165 \cdot 9-188 \cdot 1)$ \\
\hline & $64 \cdot 1(43.0-78 \cdot 1)$ & $77 \cdot 2(59 \cdot 2-104 \cdot 1)$ \\
\hline
\end{tabular}


Table 2 Mean growth velocity and weight velocity in 11 boys with anorchia and 12 with gonadotrophin deficiency before starting testosterone and during the first three years of treatment. The mean dose of testosterone for each period is also shown

\begin{tabular}{|c|c|c|c|c|}
\hline & $\begin{array}{l}\text { Before } \\
\text { treatment }\end{array}$ & $\begin{array}{l}\text { First } \\
\text { years' } \\
\text { treatment }\end{array}$ & $\begin{array}{l}\text { Second } \\
\text { years' } \\
\text { treatment }\end{array}$ & $\begin{array}{l}\text { Third } \\
\text { years' } \\
\text { treatment }\end{array}$ \\
\hline $\begin{array}{l}\text { Anorchia }(\mathrm{n}=11) \text { : } \\
\text { Mean growth velocity }(\mathrm{cm} / \text { year }) \\
\text { Mean weight gain }(\mathrm{kg} / \text { year) } \\
\text { Mean body mass index } \\
\text { Mean dose of testosterone }\left(\mathrm{mg} / \mathrm{m}^{2} / \text { month) }\right.\end{array}$ & $\begin{array}{l}5 \cdot 4 \\
3 \cdot 0 \\
18 \cdot 1 \\
\text { Not applicable }\end{array}$ & $\begin{array}{r}8 \cdot 2 \\
7 \cdot 2 \\
19 \cdot 1 \\
51 \cdot 1\end{array}$ & $\begin{array}{r}6 \cdot 9 \\
6 \cdot 6 \\
19 \cdot 7 \\
66 \cdot 7\end{array}$ & $\begin{array}{r}6 \cdot 4 \\
5 \cdot 9 \\
20 \cdot 3 \\
76 \cdot 1\end{array}$ \\
\hline $\begin{array}{l}\text { Gonadotrophin deficiency }(\mathrm{n}=12): \\
\text { Mean growth velocity }(\mathrm{cm} / \mathrm{year}) \\
\text { Mean weight gain }(\mathrm{kg} / \mathrm{year}) \\
\text { Mean body mass index } \\
\text { Mean dose of testosterone }\left(\mathrm{mg} / \mathrm{m}^{2} / \mathrm{month}\right)\end{array}$ & $\begin{array}{l}4 \cdot 8 \\
5 \cdot 0 \\
20 \cdot 6 \\
\text { Not applicable }\end{array}$ & $\begin{array}{r}7 \cdot 1 \\
6 \cdot 3 \\
21 \cdot 2 \\
50 \cdot 5\end{array}$ & $\begin{array}{r}5 \cdot 9 \\
5 \cdot 5 \\
22 \cdot 6 \\
73 \cdot 3\end{array}$ & $\begin{array}{r}5 \cdot 8 \\
5 \cdot 6 \\
23 \cdot 0 \\
85 \cdot 5\end{array}$ \\
\hline
\end{tabular}

was increased to $100 \mathrm{mg}$ every four weeks, and after another one to two years it was increased further to $250 \mathrm{mg}$ testosterone ester every four weeks. For the purpose of this study the dose of testosterone has been expressed in $\mathrm{mg} / \mathrm{m}^{2}$ surface area. Mean doses for the first, second, and third years of treatment are given in table 2 .

\section{METHODS}

Radiographs of the left hand and wrist were available for all the patients before treatment, and they were all scored by BM and MP working together using the Tanner et al RUS (radius, ulna, and short bones) method. ${ }^{8}$ To assess the reproducibility of the method, the films were then reassessed by $B M$ and MP without knowledge of the patient or the diagnosis, and the results compared. The radiographs were also assessed without knowledge of the diagnosis by DGS using the Greulich and Pyle atlas and the results compared with the initial Greulich and Pyle rating that had been carried out when the patient was first seen. ${ }^{9}$

Predictions of adult height were calculated from the RUS bone scores allocated before treatment by the method of TannerWhitehouse, ${ }^{10}$ together with the scores derived from the initial Greulich and Pyle rating' and those derived from the Bayley and Pinneau tables. ${ }^{11}$

\section{Results}

The mean growth velocities of all the patients before treatment are shown in table 2 , which also gives the mean growth velocities during the first three years of treatment, mean weight velocities, and body mass index.

In the anorchic boys, mean growth velocity during the first year of treatment increased from $5.4 \mathrm{~cm} /$ year to $8.2 \mathrm{~cm} /$ year and then fell to 6.9 $\mathrm{cm} /$ year and $6.4 \mathrm{~cm} /$ year during the second and third years of treatment, respectively. Weight gain increased from $3.0 \mathrm{~kg} /$ year to $7.2 \mathrm{~kg} /$ year during the first year of treatment, and then fell to $6.6 \mathrm{~kg} /$ year and $5.9 \mathrm{~kg} /$ year over the next two years, respectively. Body mass index (weight/ height $\mathrm{m}^{2}$ ) rose from $18 \cdot 1$ to 20.3 after three years of treatment.

In the boys with gonadotrophin deficiency, mean growth velocity increased from $4.8 \mathrm{~cm} /$ year to $7 \cdot 1 \mathrm{~cm} /$ year during the first year of treatment, and then fell to $5.9 \mathrm{~cm} /$ year and 5.8 $\mathrm{cm} /$ year over the next two years, respectively.
Table 3 Mean adult height (cm), mid-parental height, and predicted height at start of treatment calculated by TannerWhitehouse and Bayley-Pinneau methods in 11 patients with anorchia and 12 patients with gonadotrophin deficiency

\begin{tabular}{|c|c|c|}
\hline & $\begin{array}{l}\text { Anorchia } \\
(n=11)\end{array}$ & $\begin{array}{l}\text { Gonadotrophin } \\
\text { deficiency } \\
(n=12)\end{array}$ \\
\hline $\begin{array}{l}\text { Adult height } \\
\text { Mid-parental height } \\
\text { Predicted height: }\end{array}$ & $\begin{array}{l}177 \cdot 1 \\
174 \cdot 4\end{array}$ & $\begin{array}{l}176.9 \\
176 \cdot 1\end{array}$ \\
\hline $\begin{array}{l}\text { Tanner-Whitehouse } \\
\text { Bayley-Pinneau }\end{array}$ & $\begin{array}{l}177 \cdot 0 \\
178 \cdot 1\end{array}$ & $\begin{array}{l}174 \cdot 0 \\
177 \cdot 3\end{array}$ \\
\hline
\end{tabular}

Weight gain increased from $5.0 \mathrm{~kg} /$ year to 6.8 $\mathrm{kg} /$ year, and then fell to $5.5 \mathrm{~kg} /$ year and $5.6 \mathrm{~kg} /$ year over the next two years, respectively. Body mass index increased from 20.6 to 23.0 during the first three years of treatment.

The adult statures achieved by the two groups of patients are compared with midparental height and predicted adult height using the Tanner-Whitehouse and Bayley-Pinneau methods (table 3$)$. Mean adult height $(177 \cdot 1$ cm) for the patients with anorchia was slightly less than mean predicted height using the Bayley-Pinneau method $(178.1 \mathrm{~cm})$ and almost exactly the same as the mean height obtained by the method of Tanner-Whitehouse $(177 \cdot 0 \mathrm{~cm})$. Mean adult height in these patients was $2.6 \mathrm{~cm}$ above mean mid-parental height.

In the patients with gonadotrophin deficiency the mean adult height was $176.9 \mathrm{~cm}$, compared with a mean mid-parental height of $176 \cdot 1 \mathrm{~cm}$. the mean predicted height using the Bailey and Pinneau method was $177 \cdot 3 \mathrm{~cm}$ and using the method of Tanner-Whitehouse was $174.0 \mathrm{~cm}$, $2.9 \mathrm{~cm}$ less than the height attained.

\section{Discussion}

Testosterone treatment is well established in the management of delayed or absent male puberty. In an early paper, Aynsley-Green et al described the beneficial effect of treatment in a group of boys with anorchia. ${ }^{1}$ Since then there have been many accounts of its use in boys with constitutional delay of puberty ${ }^{3-5}$ and in chronic medical disorders which are associated with delayed puberty, such as cystic fibrosis. ${ }^{12}$ In addition, short term treatment with testosterone has been recommended for differentiating between constituional delay in puberty or gonadotrophin deficiency and growth hormone insufficiency. ${ }^{13}$ Treatment with testosterone is also the main method of inducing secondary sexual development in boys with hypopituitarism that is caus- 
ing growth hormone deficiency associated with gonadotrophin deficiency. ${ }^{2}$

Our results provide further evidence for the safety and efficacy of testosterone ester given by intramuscular injection to produce virilisation in boys with hypogonadism. The regimen that was used produced progressive development of the genitalia similar to that seen in normal male puberty, and in all cases development of the penis and scrotum was judged to be satisfactory after three to four years of treatment. The testosterone regimen does not completely mimic the normal changes of puberty, however, particularly with respect to the timing of peak height velocity. In normal puberty peak height velocity is reached about 18-24 months after the onset of puberty, at a time when testicular development is already well established. In this study, and in the study described by Aynsley-Green et al, ${ }^{1}$ the most rapid growth occurred during the first year of treatment, and over the next two years growth velocity declined. These findings suggest that the initial dose of testosterone used in both studies may have been too high, and it might be more physiological to use a smaller dose of depot testosterone during the early stages of androgen replacement. Despite this difference in the timing of peak height velocity, however, the regimen described seems to be associated with realisation of full growth potential, judged from both mid-parental heights and adult height predictions based on two different methods.

In our study many of the subjects did not begin treatment until well after the normal age at which puberty begins. This was at least partly related to the late referral of some patients, particularly those with gonadotrophin deficiency who had initially been considered to have straightforward constitutional delay of puberty. We emphasise that such a delay in initiating treatment is inappropriate in most cases, and that the aim of treatment should be to try to mimic the timing of normal puberty as closely as possible, probably by using a lower starting dose of testosterone than that used in our patients.

The effect of testosterone on body habitus and muscle mass is well known, and in our patients this was probably reflected in the increased body mass index that was seen with continued treatment. This increase in both anorchic and hypogonadotrophic patients was similar during a three year period. The initial body mass index was, however, higher in the hypogonadotrophic patients. We do not know whether this is a consistent feature of gonadotrophin deficiency or whether the finding could be related to the relatively advanced age at which some of the patients started treatment.
Our results also provide some information on the use of the Tanner-Whitehouse and BayleyPinneau methods of predicting adult height in hypogonadal boys. Zachman et al found the method of Tanner-Whitehouse superior to the Bayley-Pinneau method in normal children and in children with familial tall stature, whereas it overestimated adult height in various types of short stature. ${ }^{14}$ Similar observations were made by Lenko in normal Finnish children and children with growth delay. ${ }^{15}$ In our patients with anorchia the two methods gave similar height predictions, but the method of TannerWhitehouse underpredicted mean adult height in the boys with gonadotrophin deficiency.

In summary, our findings provide further evidence of the safety of testosterone replacement treatment in male hypogonadism but we suggest that an initial dose of $100 \mathrm{mg}$ every six to eight weeks may result in rather rapid growth. A lower dose of testosterone might be more appropriate in cases in which treatment is started at the age of 11 to 12 years.

1 Aynsley-Green A, Zachmann M, Illig R, Prader A. Congenital bilateral anorchia in childhood. Clinical, endocrine and therapeutic evaluation in 21 cases. Clin Endocrinol 1976;5: 381-91.

2 Aynsley-Green A, Zachmann M, Prader A. Interrelation of the therapeutic effects of growth hormone and testosterone
on growth in hypopituitarism. F Pediatr 1976;89:992-9.

3 Rosenfeld RG, Northcroft GB, Hintz RL. A prospective Rosenfeld RG, Northcroft GB, Hintz RL. A prospective
randomised study of testosterone treatment of constiturandomised study of testosterone treatment of constitu-
tional delay of growth and development in male adolestional delay of growth and devel
cents. Pediatrics 1982;69:681-7.

4 Wilson DW, Kei J, Hintz RL, Rosenfeld RG. Effects of testosterone therapy for pubertal delay. Am $\mathcal{f}$ Dis Child 1988;142:96-9.

5 Zachmann M. Use and risks of androgen therapy: replacement, constitutional delay, and tall stature. In: Forest MG, ed. Androgens in childhood; paediatric and adolescent endocrinology. Vol 19. Basle: Karger, 1989:147-63.

6 Zachmann M, Prader A. Anorchia and androgenic effect of testosterone in sexually immature boys and its dependency on growth hormone. F Clin Endocrinol Metabol 1970;30: 85-95.

7 Marti-Henneberg C, Niirianen AK, Rappaport R. Oxandrolone treatment of constitutional short stature in boys during adolescence. Effect on linear growth, bone age, pubic hair and testicular development. $\mathcal{F}$ Pediatr 1975;86. 783-8.

8 Tanner JM, Whitehouse RH, Healy MJR. A new system of estimating skeletal maturity from the hand and wrist with standards derived from a study of 2600 healthy British children. standards derived from a study of 2600 healthy British

9 Greulich WW, Pyle SI. Radiographic atlas of skeletal development of the hand and wrist. 2nd Ed. Palo Alto: Stanford ment of the hand and wrist.
University Press, 1959.

10 Tanner JM, Whitehouse RH, Cameron N, Marshall WA Healy MJR, Goldstein H. Assessment of skeletal maturity and predictions of adult height (TW2 method). London: Academic Press, 1983 .

11 Bayley N, Pinneau SR. Tables for predicting adult height from skeletal age. $\mathcal{f}$ Pediatr 1952;40:423-41.

12 Landon C, Rosenfeld RG. Short stature and pubertal delay in male adolescents with cystic fibrosis. Androgen treatment. Am $\mathcal{F}$ Dis Child 1984;138:388-91.

13 Kaplovitz PB. Diagnostic value of testosterone therapy in boys with delayed puberty. Am $\mathcal{f}$ Dis Child 1989;143. 116-20.

14 Zachmann M, Sobradillo B, Frank M, Prader A. Bayley-Pinneau, Roche-Wainer-Thissen and Tanner height predictions in normal children and in patients with various predictions in normal children and in patients with val conditions. $\mathcal{F}$ Pediatr 1978;93:749-55.

15 Lenko HL. Predictions of adult height with various methods in Finnish children. Acta Paediatr Scand 1979;68:85-92. 